The Polymorphism of Crime Scene Investigation: an Exploratory Analysis of the influence of Crime and Forensic Intelligence on decisions made by Crime Scene Examiners

Tatiana Resnikoff, Olivier Ribaux, Amélie Baylon, Manon Jendly, Quentin Rossy

Ecole des sciences criminelles, Faculty of Law, Criminal Justice, and Public Administration, University of Lausanne, CH-1015 Lausanne, Switzerland.

Corresponding author:

Olivier Ribaux

University of Lausanne

Ecole des Sciences Criminelles

Batochime

CH- 1015 Lausanne-Dorigny

olivier.ribaux@unil.ch 


\section{Acknowledgment}

We owe special thanks to the police which accepted to participate in this study, in particular members of their forensic and intelligence units. Such a study is only possible in connection with projects supported by the Swiss National Science Fundation which allow the

development of the necessary conceptual and collaborative framework in the area of forensic intelligence (e.g. SNF project no. CR21I2-35236) 


\title{
The Polymorphism of Crime Scene Investigation: an Exploratory Analysis of the influence of Crime and Forensic Intelligence on decisions made by Crime Scene Examiners
}

\begin{abstract}
A growing body of scientific literature recurrently indicates that crime and forensic intelligence influence how crime scene investigators make decisions in their practices.

This study scrutinises further this intelligence-led crime scene examination view. It analyses results obtained from two questionnaires. Data have been collected from 9 chiefs of Intelligence Units (IUs) and 73 Crime Scene Examiners (CSEs) working in forensic science units (FSUs) in the French speaking part of Switzerland (6 cantonal police agencies).

Four salient elements emerged: (1) the actual existence of communication channels between IUs and FSUs across the police agencies under consideration; (2) most CSEs take into account crime intelligence disseminated; (3) a differentiated, but significant use by CSEs in their daily practice of this kind of intelligence; (4) a probable deep influence of this kind of intelligence on the most concerned CSEs, specially in the selection of the type of material/trace to detect, collect, analyse and exploit.

These results contribute to decipher the subtle dialectic articulating crime intelligence and crime scene investigation, and to express further the polymorph role of CSEs, beyond their most recognised input to the justice system. Indeed, they appear to be central, but implicit, stakeholders in intelligence-led style of policing.
\end{abstract}

Keywords: crime analysis, forensic intelligence, intelligence-led policing, repetitive crimes, scene of crime officers, crime scene investigation 


\section{Introduction}

Police in western countries have progressively moved towards intelligence-led models of policing. The reality of this trend has been intensively studied, leading to contrasted observations [1, 2]. It is however generally not contested that intelligence-led policing constitutes a dominant stream in terms of model of security, by promoting a proactive and informed approach to security problems [3]. The role of forensic science and crime scene investigation in such models is much less scrutinised despite evident signs of their potential or actual impact on practices and decision-making processes [4-10].

Recently, some authors have proposed a framework for crime scene investigation in order to explicit this perspective [11-13]. Mostly focused on high volume and repetitive crimes, this approach extends however to all forms of crimes, including serious crimes. Consequently, this paper uses indifferently terms such as scene of crime officer, crime scene examiner (CSE) or crime scene investigator for referring to professionals whose function is to investigate crime scenes (i.e. the space delineated by the supposed dispersion of the material exchanged during an assumed litigious activity), whatever their seriousness.

This framework postulates at least three levels of knowledge influencing crime scene examination:

1. The physical level focuses on the material exchanged between the scene and the offender. It concerns the physical substrate on which the activity took place. It integrates, for instance, knowledge on typical substances transferred, mechanisms for transfer or persistence of the material on a surface according to physical circumstances. It considers the divisibility of matter [14]. Knowledge about the existence, potential and limits of methods and tools for detecting (often latent) marks, for preserving and collecting them completes this level. Forensic science focuses on this level. It provides most of models, methods, and tools. More often than not, standard operating procedures are supposed to make this knowledge operational [11].

2. The situational level relates to the interpretation of the immediate physical and social context surrounding the particular activity. It refers to crime opportunity theories [15]. The aim is to determine circumstances, specificities of victims/targets in a specific place and at a specific time, which may have influenced the modus operandi of the perpetrator. It supports thus the development of hypotheses on the activity, which, in turns, indicate possible contact points that may have caused exchange of material with the substrate $[16,17]$.

3. The crime intelligence level refers to knowledge on the crime environment and how underlying modus operandi recurrently detected in analogue situations influence, in a common way, exchanges of matters. It is actionable knowledge for CSEs, because it orients the investigation at the scene. This knowledge thus deserves, by definition, the use of the term 'intelligence'. For instance, when CSEs recognise a typical pattern at a scene, knowledge gained from previous interventions on similar cases orient the search for points of contacts in the new situation.

The framework takes also into account pragmatic constraints (time, complexity, available means - human and technological), and the consequent priorisation of interventions according to objectives. These objectives, more often than not, refer to the outcome traditionally expected from a forensic process: a collected information structured to support the decision making process of a law court. This is obviously a far too restrictive view when considering intelligence-led styles of policing. Objectives extend then to security purposes (e.g. reducing crime, diminishing harm, reassuring victims, managing risks) [3]. The developed framework 
intends thus also to structure the debate around how to combine and optimise the variety of contributions of forensic science. In turn, it clarifies the role and function of CSEs [13].

The model still needs some refinement and should be challenged further. In this paper we focus on the intelligence level, and question how it influences, effectively (or not), CSEs in their daily practice.

For this purpose, we begin by extracting from the literature different views on the role and nature of crime scene investigation. It shows the many dimensions and tensions pervading the activity. They derive from the observation that crime scene investigation serves at the same time different paradigms of security and justice. They are under-studied. We will show that the relationship between crime scene investigation and intelligence appears throughout this literature, but is poorly analysed. In order to test if an intelligence level deserves the key position proposed by Ribaux et al. [12] in their model, this study tests its actual influence in the particular context of a relatively small area in Switzerland. Specific hypothesis addressed by this research will be stated. They are tested through two questionnaires sent to CSEs and managers of intelligence units. How the questionnaires were devised is the topic of the next section. Finally, results are presented and interpreted in order to better understand the nature and role of crime scene investigation in intelligence-led policing, and the validity of the three levels model.

\section{Crime scene investigation and the role of CSEs}

Forensic science largely ignores crime scene investigation [18]. The dominant conception of the discipline is too often restricted to the operations of a laboratory (also called forensic science provider) where scientists experts extract characteristics from the material collected. There observations are interpreted systematically in the perspective of a court trial. This 'structural' view on forensic science fragment the whole treatment of forensic case data, from its collection at the scene, to its use in the many processes that may support decisions [19, 20]. Indeed, the origin of the information collected seems to belong to a separate, largely unconnected, activity.

When taken into consideration, the contribution of forensic science to crime scene investigation focuses on the expectation of the Justice System in terms of the production of evidence dedicated to a court. Validity and limit of technologies, the chain of custody, or contaminations and pollutions constitute main concerns [21]. Accreditation of procedures, validation of techniques, and certification of CSEs are seen as key objectives to reach in order to increase confidence of the Justice System in the information it uses for its decisions [22]. The court is the target that must guide all operations, from the first intervention at the scene, even if only a tiny part of the information collected will eventually influence court's decisions [23].

Research has shown that a great proportion of forensic scientists, and CSEs themselves, tend to perceive the role of CSEs exclusively along their support to the justice system, as evidence collectors [20]. This emphasis on the mechanical and controlled parts of the process may mask other roles and qualities only occasionnaly attributed to the CSEs [21].

CSEs are also recognised to assist systematically investigators in reconstructing the crime and in identifying frames of suspects. They seem to take a more integrated, yet implicit, role of advisor associated to forensic scientists of the laboratory, and to crime investigators [20, 24].

Indeed, researchers observe, by studying practices, confirmation of the existence of more extended roles for CSEs within police organisations [21, 25].These roles call for a globally 
inductive logic, which is not grasped by the mechanisation preconized by standard operating procedures [25-27].

Our study contributes to the search for a better balance between expressed and implicit processes. We postulate that intelligence influences CSEs. On the other way round, forensic case data collected at the scene also feed intelligence processes. This would explicit a role for CSEs not only as a provider to the Justice System or as an investigator but, more broadly, as a key player of proactive and intelligence-led policing [28].

The relationship between intelligence and crime scene investigation is often detected by studying various practices [4, 7, 29, 30], rather than envisaged through a formalised framework. The three levels framework mentioned above intend to fill this gap. However, it still needs to be refined $[12,13,31]$. Of importance is that it integrates an intelligence level to attest that intelligence plays a key role in crime scene investigation. This study aims at consolidating this level by questioning active CSEs in a small area of Switzerland about its reality and its form.

\section{Context of the study}

Situated at the heart of Europe (without belonging to the European Union itself), Switzerland is a federal state divided into 4 linguistic regions and hosting 8 millions inhabitants. The Swiss Confederation is composed of 26 cantons. Each runs its own autonomous police. This study focuses on the police of the French part of the country, which includes the cantons of Vaud, Genève, Valais, Fribourg, Neuchâtel and Jura ${ }^{1}$. A little less than 2 millions of people are living in this region.

The mean ratio of 2 policemen per 1000 residents has been rather stable for the last decade ${ }^{2}$. Each police is equipped with a forensic science unit (FSU). Employees of these units are both civilians coming from the School of Criminal Justice of the University of Lausanne and policemen educated and trained by the police system itslef. A significant part of academics has followed the whole, or only part, of the police education and training program. The professional structure and organisation vary however broadly from one canton to another.

Crime intelligence on high volume and repetitive crimes is produced at a local and a regional level. Each canton is operating an intelligence unit (IU). IUs are then networked to form the structure called $\mathrm{CICOP}^{3}[32,33]$. The CICOP itself is further networked with other components of the security system (e.g. border guards, police and international customs cooperation centres).

Locally, an IU gathers data from other city police covering their territories, as well as from regular interactions with various departments and by accessing a series of available database. Crime intelligence is exchanged, compared and synthesised at the regional level, and disseminated both for strategic and operational purposes through a variety of intelligence products, at the different levels, and according to different functions. Forensic case data plays a key role in feeding the sustained process operated by IUs and the CICOP. Integrated into a shared database, they help detect and monitor a significant number of crime series and improve knowledge on typical and pervasive forms of criminality [34].

\footnotetext{
${ }^{1}$ Swiss Federal Statistical Office- Effectif de population à la fin du 3e trimestre 2014: résultats provisoires. http://www.bfs.admin.ch/bfs/portal/fr/index/themen/01/01/new/nip detail.html?gnpID=2014-083 (last access, 14th Feb. 2015).

${ }^{2}$ European statistics, Eurostat, 2012, http://www.ec.europa.eu/eurostat/ (last access, 14th Feb. 2015).

${ }^{3}$ French acronym for Concept Intercantonal de Coordination Operationnelle et Préventive.
} 
The main recipients of crime intelligence products are patrols and investigative units [33]. What about forensic science units? Do intelligence products reach them? To which extend intelligence is perceived and practically used within these units? Is this information tailored for CSEs concerns?

We limit our approach to two specific, but important intelligence products: knowledge about current crime series (similar crimes perpetrated by the same offender or group of offenders) [35], as well as crimes resulting from typical opportunities, also called phenomenon [36]. These criminal phenomena may or may not be perpetrated by the same offenders or group of offenders. Throughout the text, intelligence is used as actionable knowledge related to these definitions.

Of importance is to mention that crime intelligence is not restricted to the information analysed and disseminated by Intelligence Units, but extends to informal exchanges between CSEs themselves, as well as with crime investigators or other entities (e.g. prevention units, patrols units).

\section{Specific questions addressed}

In accordance with Roux et al. [22], we will use the term 'trace' to denote all (physical) remnants of a crime activity. This is to avoid the term 'evidence', which too early in the process gives the flavour of a court of law $[37,38]$.

We consider that crime scene investigation can be expressed along three processes requiring many decisions of different nature to be made $[4,6,24]$ :

- The intervention, from the realisation that a crime occurred to the arrival at the scene (if the scene should be attended by crime scene examiners);

- Crime scene investigation itself, leading to the detection, observation and collection of material;

- The exploitation of the material collected.

According to this definition, four hypothesis are addressed in this study:

H1 Intelligence products disseminated by the CICOP and local IUs are effectively made available to CSEs.

H2 CSEs consider these intelligence products.

H3 CSEs use available intelligence to guide crime scene investigation

H4 Intelligence has an influence on decision-making processes at the three stages of crime scene investigation. It influences:

1. managerial doctrines of intervention

2. the nature and type of traces collected

3. the nature and type of traces exploited

\section{Methodology}

Two electronic and self-administrated questionnaires have been designed in order to test these hypotheses.

The first questionaire was sent to all employees (both civilian and policemen $-\mathrm{N}=117$ ) operating in FSUs over the region under consideration. 73 questionaires were returned and have been analysed, representing a $62,4 \%$ participation rate (see Table 1 ). 
Table 1: Distribution of CSEs by cantonal FSUs and participation rates

\begin{tabular}{|c|c|c|c|}
\hline Cantons & $\begin{array}{c}\text { Total number of CSEs by } \\
\text { FSUs }\end{array}$ & $\begin{array}{c}\text { Number of CSEs who } \\
\text { participated }\end{array}$ & Participation Rates \\
\hline Vaud & 19 & 12 & $63,2 \%$ \\
\hline Valais & 10 & 10 & $100 \%$ \\
\hline Fribourg & 16 & 13 & $81,2 \%$ \\
\hline Neuchatel & 15 & 11 & $73,3 \%$ \\
\hline Geneva & 48 & 10 & $20,8 \%$ \\
\hline Jura & 9 & 4 & $44,4 \%$ \\
\hline Blind canton $^{4}$ & - & 13 & - \\
\hline Total & 117 & 73 & $62,4 \%$ \\
\hline
\end{tabular}

This questionnaire was structured around three sections in order to collect information regarding: (1) the dissemination of intelligence products ${ }^{5}$ by IUs and how they reach CSEs (e.g. modes and frequency of dissemination, how CSEs are made aware of these products, what is the perception of CSEs about them $)^{6}$; (2) the crime scene investigation process and its three phases (i.e. use of available intelligence compared to other factors identified in the literature, intelligence influence on practices) and (3) the biographical data of respondents such as gender, age, training and education, professional experience, and operating unit. These data have been used as control variables during our analysis.

Table 2 provides an example of the questions used by section ${ }^{7}$.

Table 2: Sample of questions asked to CSEs by section

\begin{tabular}{|l|l|}
\hline Sections & Questions \\
\hline (1) Dissemination of & $\begin{array}{l}\text { Do you receive written documents containing information related to } \\
\text { intelligence products } \\
\text { to CSEs by IUs }\end{array}$ \\
& $\begin{array}{l}\text { Proposed response: Yes/No/Do not want to answer } \\
\text { If yes: }\end{array}$ \\
\hline
\end{tabular}

${ }^{4} 7$ questionnaires that were too incomplete have not been used (less than 3 answers by questionnaire) and 13 CSEs dit not mention their working canton. However, to take into account their responses during our analysis those have been considered as being part of the "blind canton".

${ }^{5}$ In the questionnaires, the term « informations » has been used in place of «intelligence ». This choice results from a supposed discrepency in its understanding by CSEs, as well as its negative conotation. Particularly in Switzerland, where the police has been severly blamed during the 90 s for having violated civil liberties in recording huge amount of information about the population.

${ }^{6}$ A preliminary question has been integrated into the questionnaire in order to ensure that CSEs where aware about the difference meant between a series of crime, and a typical crime phenomenon.

${ }^{7}$ For the purpose of this article the questions have been translated from French to English. 


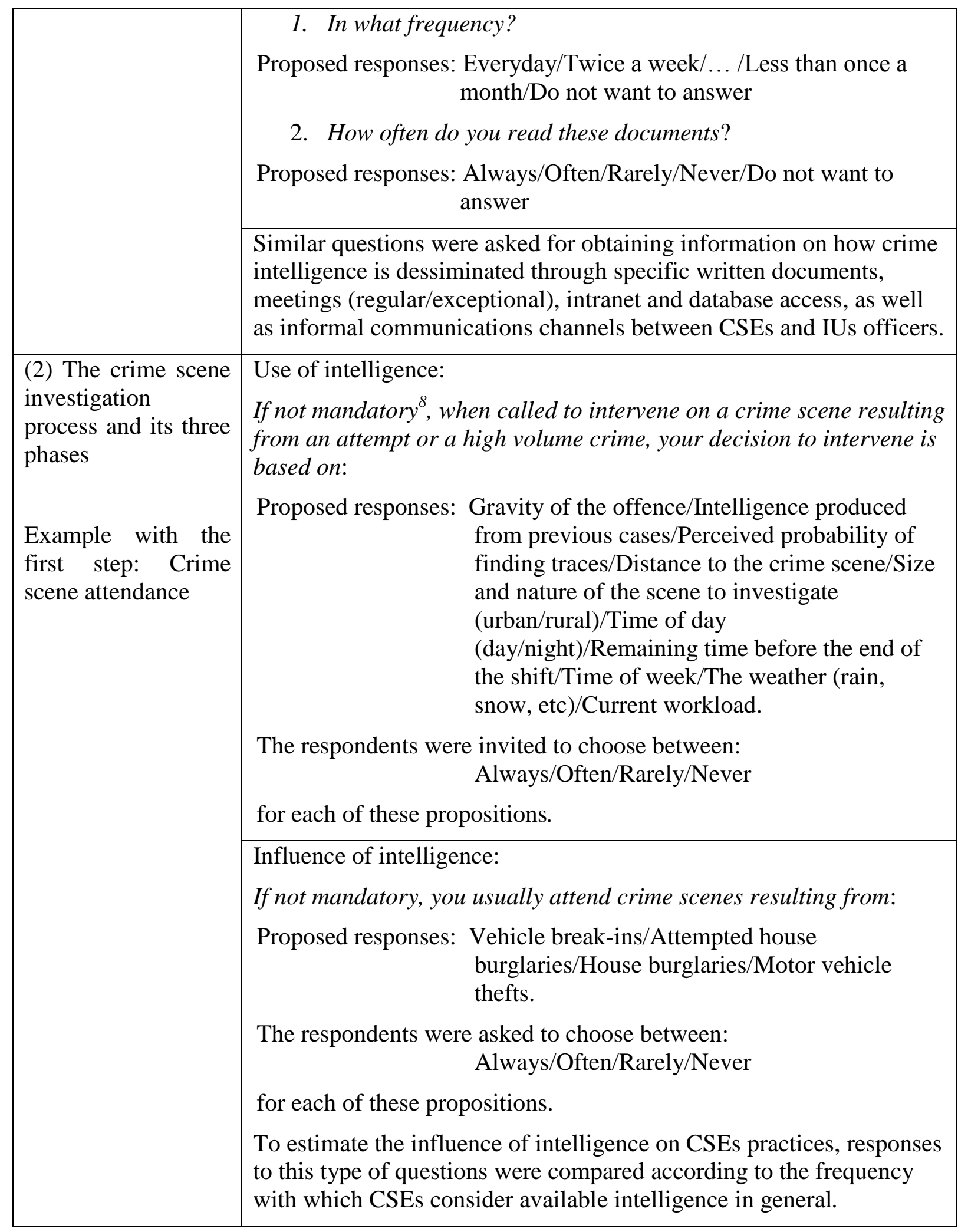

The questionnaire was composed of 36 questions. Except for four of them, all questions were structured following a closed multiple response format (e.g. Always/Often/Rarely/Never). In

\footnotetext{
${ }^{8}$ Previous to this question, respondents were asked to specify if the attendance of the crime scenes of interest in this study was mandatory. This disctinction was necessary to compare CSE's practices.
} 
the first section of the questionnaire, the decision was made to use mostly filter questions and, when needed, detailed questions. In its second section, we used matrix questions, which allow the respondents to give their opinion on different proposals, according to different types of assessment. Matrix questions were preferred as they can address various questions simultaneously, which reduces at the same time the size of the questionnaire [39].

In order to limit influences on respondents, no direct question related to the use and influence of intelligence has been formulated ${ }^{9}$. Chi- 2 correlation tests have been used to compare CSEs typical attitudes and practices according to the frequency with which they consider available intelligence produced by Intelligence Units (always/often versus rarely/never) ${ }^{10}$.

The second questionnaire composed of 20 questions was sent to managers of Intelligence Units in the 6 cantons $(\mathrm{N}=10)$. Their responses have been compared to those provided by CSEs regarding the dissemination of intelligence products. This questionnaire was very similar to the first section of the other one. It covered modes and frequencies of intelligence dissemination, using close-ended questions as well. 9 questionnaires over 10 have been analysed (participation rate of $90 \%$ ).

A pre-test has been previously organised. It has been carried out in another police agency (canton of Bern) in order not to reduce the population studied. This operation has resulted in an adjustment of the questionnaires. Some specific questions taking into account specificities of French speaking police have also completed the initial formulation based on the scientific literature.

\section{Results}

\subsection{Intelligence products are actually made available by IUs to CSES}

The following results came from responses obtained from managers of IUs $(n=9)$ and from CSEs $(n=73)$.

Some differences (inter IUs and intra FSU) are observed in terms of modes ${ }^{11}$ and frequency of diffusions. Intelligence products from IUs and CICOP are disseminated on a regular basis to CSEs, whatever the police agency. They are mostly disseminated through databases or an intranet (74\%). In all cantons, respondents attest that informal communications channels between IUs officers and CSEs are initiated from both sides $(78,1 \%)$. A significant proportion of CSEs are receiving specific ${ }^{12}$ and/or systematic written documents (respectively $61,6 \%$ and $60,3 \%$ ). They also affirm being invited at regular and/or exceptional meetings where intelligence is disseminated (respectively $49,3 \%$ et $39,7 \%$ ).

The density of the population covered by the police agency, the number of reported crimes in the canton, the physical/organisational proximity between units (IUs and FSUs), and the number of CSEs operating within FSUs seem to have no influence on the intelligence dissemination (mode and frequency). The formal or informal mode of transmission does not influence this result.

\footnotetext{
${ }^{9}$ For example, direct questions like «Do you use intelligence available (...)?», or « does intelligence influence your decisions (...)? » have not been asked.

${ }^{10}$ The number of respondents being relatively low (73 CSEs), multivariate analysis were not relevant.

${ }^{11}$ Both questionnaires distinguish carefully formal (reports, meetings) and informal (informal meetings, punctual demands) dissemination, as well as the action of making information available (database, intranet).

${ }^{12}$ In order to refine results, a distinction has been integrated between systematic and specific documents, as well as between regular and exceptional meetings.
} 


\subsection{CSEs consider intelligence products}

Results presented in the following sections are based on the responses obtained from CSEs $(n=73)$.

A significant majority of CSEs considers the available intelligence even if some of them seem more concerned than others. Almost 54\% of CSEs pretend to always/often consider intelligence products formally or informally disseminated. This subpopulation is principally constituted by males $(60,5 \% \text { males vs. } 43,7 \% \text { females })^{13}$, aged 40 to $55(66,7 \%$ vs. $51,2 \%$ in those aged 24 to 39) with an academic background acquired principally from the forensic school of University of Lausanne (63,6\% vs. $50 \%$ in those with a police background), and 15 years or more experience in crime scene investigation within a FSU $(66,7 \%$ vs. 54,5\% in those with less than 15 years of practice).

Only one respondent stated never consider intelligence produced within his/her organisation, without specifying the reasons why.

$84,9 \%$ of respondents considered intelligence related to crime series and typical crime phenomena as useful. The three main reasons reported are: (1) intelligence improves their knowledge on crime series and typical crimes (29\%), (2) intelligence allows them to orient their approach at the crime scene $(25,8 \%)$, and (3) intelligence allows them to chose which scene is worth to be investigated and to orient their approach at the scene $(21 \%)$.

However, only $10 \%$ of CSEs indicate the use of intelligence as a way to simplify their work and crime investigation.

$46 \%$ of CSEs responded rarely or never considering intelligence produced by IUs or the CICOP (with the exception of specific documents). This result does not necessarly mean that these CSEs are not interested in intelligence. It may be explained by a lack of time resulting from high pressures and workload and/or a difficult access to intelligence products poorly "publicized". They may also consider that these products are not tailored for their specific needs, their colleagues CSEs already provide sufficient intelligence informally or that they are able, through lessons learned from their own experience, to infer themselves what is the adequate attitude at the scene.

\subsection{CSEs use frequently intelligence to guide crime scene investigation}

\subsubsection{Intelligence and crime scene attendance}

When called to intervene on a crime scene resulting from an attempt or a high volume crime such as a burglary, a car theft or a car break-in, CSEs can have the latitude to choose to attend the scene or not (depending on the police management type). When it is the case, more than $70 \%$ of CSEs pretend to always or often consider intelligence produced from previous cases.

According to $60 \%$ of them, intelligence can help them identify if the new case is part of a known crime series and/or a known crime phenomenon. In that case, they consider the case as more 'important'. Their interest on the case also increases since they can evaluate, from previous experience, their chance of finding material and traces. This observation confirms recurring results from the literature, where 'importance, ${ }^{14}$ and 'chance to find relevant

\footnotetext{
${ }^{13}$ This observation is not surprising since the proportion of female is relatively low within FSUs and within our respondents.

${ }^{14}$ The importance of a case increase when related to a crime series or a typical crime phenomenon, which themselves are considering to cause significant harm.
} 
material at the scene' are the two main criteria determining the relevancy of crime scene attendance $[4,6,12,30,40]$.

This knowledge of crime series and phenomena seems however not only coming from structured intelligence products disseminated by IUs. Among CSEs who reported often to always base their decisions on this criterion, $46 \%$ recognise rarely or never consider intelligence disseminated by IUs (against $97 \%$ who reported always/often taking it into consideration). It is thus probable that intelligence comes also from other sources than IUs. Forensic intelligence provided, informally or formally, at the level of their unit probably explains an important part of this discrepancy. Crime investigators, patrols officers or direct contact with other entities (intern/extern to their police) concerned by those crimes offer also other possible channels for generating crime intelligence.

Interestingly, CSEs specify that they never or rarely base their decision to attend - or not - a scene on the nature or extend of the space to investigate, on the period of the week (working days or week-ends), on the time remaining before the end of a shift, or on the weather. However, more than $20 \%$ of CSEs often consider workload and time of day (day or night) when making their decisions.

\subsubsection{Intelligence and crime scene processing}

Two third of CSEs recognise using their own experience and knowledge as well as intelligence to guide them during crime scene processing, when they suspect the case to be part of a crime series/phenomenon. However, more than 20\% reported adopting the same approach whatever the case type (e.g. high volume crime, serious crime).

When comparing CSEs that always or often consider intelligence to those who rarely or never consider it, we observe a noticeable difference. More than $80 \%$ of CSEs who reported always or often consider intelligence produced by IUs reported using intelligence in this phase. Among those who rarely or never consider intelligence produced by IUs, 46,2\% of CSEs still reported using intelligence to guide them during crime scene processing.

Once again, results tend to show that CSEs rely not only on intelligence produced by IUs but also on intelligence disseminated through other channels such as exchanges with immediate colleagues and other entities. Use of available intelligence as well as use of experience and personal knowledge could be explain by the fact that they can give specific informations regading the nature, the quantity, the quality and the location of traces potentially present on the crime scene.

\subsubsection{Intelligence and trace selection for exploitation}

More than $68 \%$ of CSEs reported often to always base the selection of traces to be exploited on intelligence available. Knowledge of previous cases allows targeting the most promising kinds of forensic case data in the context of a series or a typical crime phenomenon. It may constitute the main motivation for using crime intelligence [12].

An example of the form such a mechanism can take, is provided by Baylon [41]. When CSEs recognise a new case of house burglary as belonging to a typical phenomenon, they generally collect latent biological material at a particular commonly identified point of contact (on the window of the premises). It is assumed that the specific modus operandi used by perpetrators in this kind of situations creates exchange of biological material at this specific point. Swabbing at this point is part of a routine approach when processing such scenes. However, during the investigation of a crime scene belonging to this phenomenon, the specimens collected sent to the laboratory did not provide a DNA profile. The situation was then reassessed by the forensic science unit. The focus turned towards other kinds of traces that were 
regularly noticed on similar cases (e.g. shoemarks). The forensic science unit itself (and not IUs) provided forensic intelligence that resulted in a change in the way scenes were processed. An assessment of the crime environment led to revise practices and guide the selection of traces to focus on, specifically according to these types of cases.

Intelligence is however relegated to the fourth position among the criteria considered as influential on trace selection. It comes after the perceived quality of traces (95\%), personal experience and knowledge $(91,7 \%)$ and the nature of the traces $(71,7 \%)$. Fewer respondents seem to rely on technical resources available $(66,7 \%)$, exploitation costs $(36,7 \%)$, available time $(33,3 \%)$ and necessary time to analyse the material $(10 \%)$.

CSEs who said taking often to always note of intelligence provided by IUs are however much more numerous to base their selection on all types of intelligence $(82,9 \%$ vs. $48 \%)$.

Once again, intelligence is recognised not being provided exclusively by IUs. There is however a strong correlation between interests in intelligence in general to support decisions in all stages of crime scene investigation, and interest in intelligence provided by IUs.

\subsection{A likely influence of intelligence on crime scene investigation process}

\subsubsection{Doctrine of intervention}

When the intervention is not defined as mandatory by an internal procedure, most CSEs do not attend cases of vehicles break-in (75\%), attempted house burglaries $(73,5 \%)$ and motor vehicles theft $(62 \%)$. The only exception concerns house burglaries: 68,9\% of CSEs often choose to attend such scenes, even when there is no pressure from their hierarchy the management.

These results confirm observations made by Adderley et al. [42], Baylon [41] and Jansson [43] that high volume crimes rarely constitute a priority in terms of crime scene attendance.

It appears from the data that CSEs who reported taking into consideration often to always intelligence provided by IUs intervene more often on house burglaries cases $(86,7 \%$ vs. $35,7 \%)$. A smaller influence is also observed for cars break-in (28,9\% vs. $13,3 \%)$. However no difference is noticeable between CSEs who consider intelligence and the ones who do not regarding intervention on attempted burglaries $(26,3 \%$ vs. $26,7 \%)$ or vehicles theft $(33,3 \%$ vs. $34,6 \%)$.

In summary, intelligence does not have a great influence on general doctrine of intervention, even when CSEs have certain latitude to make their own decisions. Only house burglaries and, to a lesser extent, car break-ins are exceptions. Some case studies have also shown that this influence may appear when considering singular cases. For instance, when a car theft has been connected through the analysis of data with a robbery, if the car is recovered, it is obviously generally investigated by CSEs (it becomes part of the robbery).

\subsubsection{Likely influence of intelligence on the nature and quality of traces detected}

CSEs focus their search differently depending on the type and quality of trace [27].

A trace can come from a person or be caused by an object. These traces may be of different qualities (e.g. very fragmentary or supposed to contain a lot of information from its source).

Of course, high quality traces coming from persons have intuitively the favour of CSEs. As they match criteria for using databases, they promise the possibility of a direct identification of the perpetrator, and they allow a more comfortable situation for forensic experts, if the trace has to be evaluated for court purpose. 


\subsubsection{The nature of traces searched for and collected}

CSEs search for and collect preferably traces coming from persons, rather than traces coming from objects. All CSEs reported searching always or often material likely to provide a DNA profile or fingermarks. Among them, almost 94\% indicated searching always or often also other kind of traces coming from a person, such as earmarks or footmarks. Marks coming from an object such as tool marks or fibers are less frequently searched for. More than two third of CSEs reported searching rarely or even never such marks, at the exception of shoemarks. This choice may be influenced by a specific forensic culture developed in the region $^{15}$.

These results are in line with numerous researches available on this topic [42, 44-47].

Of importance is to notice that CSEs who indicate taking into consideration regularly intelligence produced by IUs seem to show not only more interest on traces coming from persons, but also on traces coming from objects (Tables 2 and 3). Among them, almost 60\% reported often to always search for object traces, other than shoemarks. Among CSEs who rarely or never take into consideration intelligence, only $50 \%$ rarely search for material coming from objects.

Table 3: Traces coming from persons - Traces searched by CSEs, and frequency with which they take into consideration intelligence disseminated by IUs $(n=66)$.

\begin{tabular}{|c|c|c|c|c|c|c|}
\hline \multirow{3}{*}{$\begin{array}{l}\text { CSEs consider } \\
\text { intelligence }\end{array}$} & \multicolumn{6}{|c|}{ Proportion of CSEs searching for traces coming from persons } \\
\hline & \multicolumn{2}{|c|}{ DNA } & \multicolumn{2}{|c|}{ Finger marks } & \multicolumn{2}{|c|}{ Other traces (person) } \\
\hline & $\begin{array}{l}\text { Often to } \\
\text { always }\end{array}$ & $\begin{array}{c}\text { Rarely to } \\
\text { never }\end{array}$ & $\begin{array}{l}\text { Often to } \\
\text { always }\end{array}$ & $\begin{array}{c}\text { Rarely to } \\
\text { never }\end{array}$ & $\begin{array}{l}\text { Often to } \\
\text { always }\end{array}$ & $\begin{array}{l}\text { Rarely to } \\
\text { never }\end{array}$ \\
\hline Always & $94,4 \%(34)$ & $90 \%(27)$ & $88,9 \%(32)$ & $86,7 \%(26)$ & $69,4 \%(25)$ & $56,7 \%(17)$ \\
\hline Frequently & $5,6 \%(2)$ & $10 \%(3)$ & $11,1 \%(4)$ & $13,3 \%(4)$ & $27,8 \%(10)$ & $33,3 \%(10)$ \\
\hline Rarely & - & - & - & - & $2,8 \%(1)$ & $10 \%(3)$ \\
\hline Never & - & - & - & - & - & - \\
\hline
\end{tabular}

Table 4: Traces coming from objects - Traces searched by CSEs and frequency with which they take into consideration intelligence disseminated by IUs $(n=66)$.

\begin{tabular}{lcccc} 
& \multicolumn{4}{c}{ Proportion of CSEs searching for traces coming from objects } \\
\cline { 2 - 5 } $\begin{array}{l}\text { CSEs consider } \\
\text { intelligence }\end{array}$ & \multicolumn{2}{c}{ Shoemarks } & \multicolumn{2}{c}{ Other traces (objects) } \\
& Often to always & Rarely to never & Often to always & Rarely to never \\
Always & $100 \%(36)$ & $100 \%(30)$ & $19,4 \%(7)$ & $0 \%(0)$ \\
Often & - & - & $38,9 \%(14)$ & $0 \%(0)$ \\
Rarely & - & - & $38,9 \%(14)$ & $50 \%(15)$ \\
Never & - & - & $2,8 \%(1)$ & $50 \%(15)$ \\
\end{tabular}

\footnotetext{
${ }^{15}$ Girod et al. (2008) explained a specific interest for shoemarks in the region under consideration through the influence of researches carried out in this field at the School of criminal justice of the University of Lausanne.
} 
Most CSEs who reported often to always considering intelligence specified being interested in object traces because they may:

- Help reconstruct the event and understand the modus operandi of the perpetrator $\left(61,9 \%^{16}\right)$;

- Have recognised similarities with traces collected from other cases (e.g. shoe sole pattern or singularities) $(61,9 \%)$;

- Bring new light on a crime series or a crime phenomenon $(57,1 \%)$;

- Help confirm that the case belongs to a crime series or a specific phenomenon $(52,4 \%)$.

These results are in line with the elementary proposition [22, 28, 45, 48], which state that forensic case data do not only serve a court to form its decisions, but feed many other processes related to crime investigation or more broadly to knowledge about crime that may support other security purposes.

\subsubsection{The quality of traces searched for and collected}

CSEs mostly focus their search and collection on high quality traces, but a significant part of them (47\%) also reported searching often to always for fragmentary traces. There seem to be an acceptable limit in terms of quality, as all respondents recognised only rarely to never search for very fragmentary (poor quality) traces ${ }^{17}$. These results support modestly the observations made for instance by $[6,49]$, who reported that the search for fragmentary traces is rare.

However, CSEs who often to always consider intelligence tend to more often search for fragmentary traces, in comparison with CSEs who do not show interest ( $80 \%$ vs. 3,4 \%). The same CSEs interested in intelligence are more prone to search for very fragmentary traces (respectively $77,1 \%$ vs. $24,1 \%$ ).

CSEs explained their interest for fragmentary traces when they:

- Have already been observed on previous cases (e.g. patterns, singularities) $(64,7 \%)$;

- Tend to link the new case with previous ones $(58,8 \%)$;

- Support the comprehension of the development of a series or bring knowledge on the understanding of a crime phenomenon $(50 \%)$;

- Support the understanding of the modus operandi $(44,1 \%)$;

- May support an identification process, despite their poor quality $(41,2 \%)$.

Beyond strongly supporting $\mathrm{H} 4$, these results also re-confirm the hypothesis formulated by $[18,46]$, who stated that CSEs interested in intelligence would be more prone to search for and extract information that may go beyond the direct identification of a person, in order to bring new light on a crime problem. Even if this information is of poor quality.

\footnotetext{
${ }^{16}$ This pourcentage corresponds to the proportion of CSEs who estimate this proposition as the most important compared to the other propositions. The interpretation is the same for the following pourcentages.

${ }^{17}$ The question distinguish three levels of quality : good quality (perceived as sufficient to identify the source) ; poor quality (e.g. percieved fragmentary) and very poor quality (e.g. perceived very fragmentary).
} 


\subsubsection{The exploitation of traces collected}

During this phase, a triage takes place in order to select the collected traces that are evaluated as worth to be examined or immediately confronted to databases. Otherwise traces are preserved for a possible future use.

This process and the related decisions are obviously linked to the previous phase of crime scene investigation (trace selections at the scene). This is why results are presented within a similar structure, in regard with the nature and quality of traces exploited.

\subsubsection{The nature of traces exploited}

Not surprisingly, all CSEs affirmed using often to always traces coming from persons (in fact mostly DNA profile and fingermarks), while the use of object traces remains less frequent. The only exception concerns once again shoemarks, as a probable effect of a specific forensic culture among CSEs.

Moreover, there is no much difference between CSEs who often to always consider intelligence and CSEs who do not. Only exception, CSEs who consider intelligence more often tend to exploit more frequently traces coming from objects (Tables 4 and 5).

Table 5: Traces coming from persons - Traces exploited by CSEs and frequency with which they take into consideration intelligence disseminated by IUs $(n=60)$

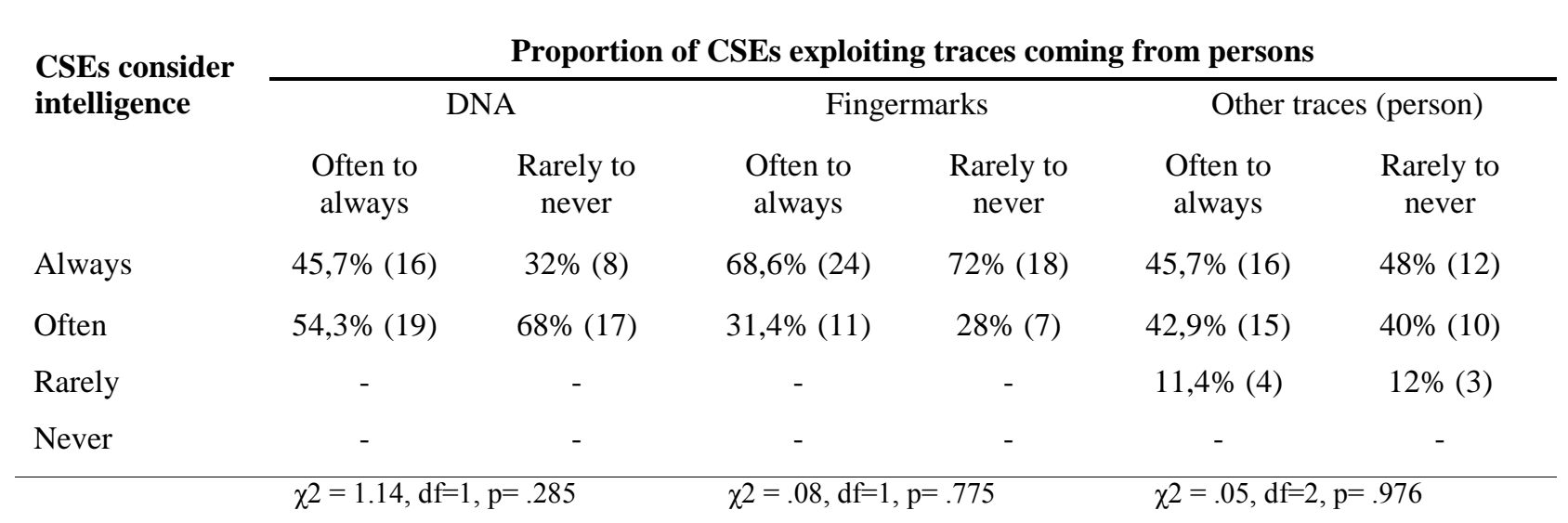

Table 6: Traces coming from objects - Traces exploited by CSEs and frequency with which they take into consideration intelligence disseminated by IUs $(n=60)$.

\begin{tabular}{lcccc} 
& \multicolumn{4}{c}{ Proportion of CSEs exploiting traces coming from objects } \\
\cline { 2 - 5 } $\begin{array}{l}\text { CSEs consider } \\
\text { intelligence }\end{array}$ & \multicolumn{2}{c}{ Shoemarks } & \multicolumn{2}{c}{ Other traces (objects) } \\
& Often to always & Rarely to never & Often to always & Rarely to never \\
Always & $77,1 \%(27)$ & $72 \%(18)$ & $5,7 \%(2)$ & $0 \%(0)$ \\
Often & $22,9 \%(8)$ & $28 \%(7)$ & $54,3 \%(19)$ & $4 \%(1)$ \\
Rarely & - & - & $40 \%(14)$ & $0 \%(12)$ \\
Never & - & - & $\chi 2=29, \mathrm{df}=3, \mathrm{p}=.000$
\end{tabular}

These results point in the same direction as those observed in 6.4.2.1. The motivation of bringing new light on crime problems, beyond the direct identification process in the perspective of the apprehension of a suspect and his presentation to a Court, seems to have an 
effect on the variety of information exploited by CSEs [18, 42, 45-47].

\subsubsection{The traces relevancy}

CSEs had to estimate to which frequency the traces they have collected have proved to be relevant after they were analysed and interpreted.

More than two third of CSEs reported exploiting often to always relevant traces. This may reflect social desirability rather than reality [50]. It is however particularly remarkable that CSEs, who take into consideration intelligence, reported exploiting much more frequently relevant traces than CSEs who broadly ignore available intelligence (respectively 91,4\% against $36 \%$ ).

These results seem to show that CSEs mostly agree with a hypothesis formulated by [12]. It states that intelligence can support the search for relevant traces (i.e. traces linked with the case and bringing a significant piece of information).

\subsubsection{The quality of exploited traces}

Only a minority of CSEs reported exploiting fragmentary traces (always or often), whatever the objectives: better understanding the event and the modus operandi $(43,4 \%)$, reducing the frame of suspects (40\%), linking cases $(36,6 \%)$, or improving knowledge about a series or criminal mechanisms $(35 \%)$.

However, once again those who more often consider intelligence produced by IUs are more prone to use fragmentary traces, than those who rarely/never consider it (Table 6).

Table 7: Fragmentary traces exploited by CSEs and frequency with which they take into consideration intelligence disseminated by IUs ( $\mathrm{n}=60)$

\begin{tabular}{lcccccccc}
\multirow{2}{*}{$\begin{array}{l}\text { CSEs consider } \\
\text { intelligence }\end{array}$} & \multicolumn{7}{c}{ Activity/MO } & \multicolumn{2}{c}{ Reducing the frame } & \multicolumn{2}{c}{ Linking } & \multicolumn{2}{c}{ Understanding } \\
& $\begin{array}{c}\text { Often } \\
\text { Always }\end{array}$ & $\begin{array}{c}\text { Rarely } \\
\text { Never }\end{array}$ & $\begin{array}{c}\text { Often } \\
\text { Always }\end{array}$ & $\begin{array}{c}\text { Rarely } \\
\text { Never }\end{array}$ & $\begin{array}{c}\text { Often } \\
\text { Always }\end{array}$ & $\begin{array}{c}\text { Rarely } \\
\text { Never }\end{array}$ & $\begin{array}{c}\text { Often } \\
\text { Always }\end{array}$ & $\begin{array}{c}\text { Rarely } \\
\text { Never }\end{array}$ \\
Always/Often & $71,4 \%$ & $4 \%$ & $54,3 \%$ & $20 \%$ & $51,4 \%$ & $16 \%$ & $48,6 \%$ & $16 \%$ \\
& $(25)$ & $(1)$ & $(19)$ & $(5)$ & $(18)$ & $(4)$ & $(17)$ & $(4)$ \\
Rarely/Never & $28,6 \%$ & $96 \%$ & $45,7 \%$ & $80 \%$ & $48,6 \%$ & $84 \%$ & $51,4 \%$ & $84 \%$ \\
& $(10)$ & $(24)$ & $(16)$ & $(20)$ & $(17)$ & $(21)$ & $(18)$ & $(21)$ \\
\hline
\end{tabular}

These results support our hypotheses $\mathrm{H} 4$ since crime intelligence seems to have an influence on CSE's practices. CSEs who show an interest in intelligence by taking often note of it tend to have a inclination to exploit more frequently traces coming from objects, as well as relevant and fragmentary traces in order to bring information to various intelligence processes, compared to those who are less engaged in intelligence.

\section{Discussion / Conclusion}

This study contributes to the increasing body of literature focusing on crime scene investigation and its relation to crime and forensic intelligence. It reports attitudes and 
implicit practices, which are otherwise not grasped by the standard operating procedures proliferating in this field.

This is an exploratory study, because the number of respondents remains small. In addition, it covers a specific region where the influence of the University on forensic and intelligence practices may distort perceptions. This is due to the fact that forensic science and intelligence units are staffed by alumni from the School of Criminal Justice, and its forensic branch at University of Lausanne. The generalization of the results should thus be taken with caution. Moreover, this study was not designed to assess the impact of intelligence on the improvement of the 'efficiency' of crime scene investigators, whatever this term would mean. This aspect was thus not measured. The interest of CSEs in crime and forensic intelligence and the specific influence of intelligence in guiding the process have been however documented and clarified.

With reference to our hypotheses, the results show the following:

1. Most CSEs consider crime intelligence when they have to decide to attend a crime scene or not. In particular, they consider such a knowledge as important since it can help them identify if a case is part of a known crime series and/or of a known crime phenomenon and shed light on typical forms of crimes. This kind of approach is generally inopposed to the way organisations tend to manage high volume crimes [41-43]. They prefer to classify events according to their gravity (serious, crime against persons, high volume), or consider criteria such as the value of stolen goods when dealing with burglary for example. By using such criteria, organisations deviate from basic principles of intelligence-led policing, where burglaries should be seen as a serial crime, highly concentrated, and in particular caused by prolific offenders. An attempted burglary crime scene with relevant information available may be much more important to target prolific offenders than a case with high value stolen goods. In other words, organisations remain largely focused on single and separated events, scored as more or less important with regards to the law.

2. Most CSEs use available crime intelligence as well as their own knowledge and experience to target their search during crime scene processing. They also choose what is worth to be collected, not only for court purpose, but also much more broadly, in regard with the whole crime environment.

3. Most CSEs recognise the value of intelligence in a triage process consisting of selecting the collected traces worth to be exploited. This is of high importance in regards with backlogs and costs that impose organisations to adopt a rational selection process [24, 41].

4. Results eventually show some reciprocity between FSUs and IUs. IUs provide intelligence that influence crime scene investigation. Conversely, information provided by traces collected at the scene feed intelligence process. This concern appears clearly with the collection of traces of lower quality than generally required (or perceived to be required) by the justice system. This information is entirely dedicated to a better understanding of modus operandi, crime systems, or more broadly, crime environment.

Our approch is thus, at this stage, descriptive, rather than a prescription of how CSEs should operate. Indeed, the use of crime intelligence in crime scene investigation immediately resonates with cognitive biases [51-54]. Risks to create undesirable effects by disseminating crime intelligence exist. Crime scene investigators would generally tend to focus on what they or their organisation know and prioritise. This could lead to forget the singular nature of crime events, and hamper the discovery of new crime mechanisms. For this reason, some would argue that crime intelligence must be masked to crime scene investigators. 
We do not agree with this position. First, regardless of the approach, crime scene investigation is not a passive process. It necessitates the development of conjectures about what occurred, and the use of knowledge of different types. Without knowledge of different kinds and hypotheses, it would be difficult to explain how traces are detected and collected. Removing crime intelligence from crime scene investigation would obviously create a net lack of information on how to make decision for efficiently addressing high volume crimes. Second, crime and forensic intelligence is generally much more neutral than common interpretation of the term 'intelligence' may suggest (e.g. pointing systematically towards persons, surveillance or National security). Disseminating information such that 'a specific sole pattern has been recurrently observed on recent burglary cases' is of a very different nature. This is why we have used throughout the texte the term 'crime intelligence' or 'forensic intelligence', rather than solely 'intelligence'.

Biases induced by a priori knowledge, as well as by emotions (probably very impactive for CSEs) obviously have to be mitigated by complementary mechanisms. They should anyhow not be addressed by removing from the methodology information guiding efficiently to the detection of relevant traces.

Results obtained tend to show that CSEs interested in crime intelligence perceive their role in accordance with broader intelligence-led policing frameworks, rather than exclusively from a legalist point of view. The tensions however pervade, and this extended role remains most of the time more implicit than explicit within police organisations.

This hypothesis is of great importance in regards with evolutions of forensic science. An increasing pressure tends to force the accreditation of crime scene investigation units and procedures. This necessarily favours a mechanical and controlled view of procedures at the scene, in order to bring information in the way required by the justice systems and for court purposes. This legalist approach tends to dismiss any kind of intelligence from crime scene investigations in order to avoid cognitive biais (contextual effects). However, the lack of interest by the forensic science community for this rationality may lead to many misunderstandings and paradoxes. This places CSEs in a very uncomfortable position, inbetween two conceptions, poorly expressed and difficult to articulate. The prescriptive nature, deprived from contextual information, preconized by the legalist approach, contrasts with abilities to associate ideas, develop conjectures and interpret information within a context provided by intelligence and investigative frameworks. If training and education focus exclusively on mechanical, formalised, required, and controlled dimensions of the processes, this will necessarily reduce the capacity of organisations to improve their knowledge of the crime environment. Traces will not feed adequately intelligence processes, while they constitute the more objective and solid information on crimes. The rationality of organisations for devising efficient policing would be greatly impacted.

This debate will necessarily continue, as the legalist approach meets many challenges and show to be largely in crisis within laboratories [22]. From this side, how intelligence-led policing is really implemented is still controversial [3]. Further studies are necessary, for instance to investigate whether CSEs - who are taking into consideration and are using intelligence - actually collect different types of traces, or whether they provide a broader spectrum of information to their organisation. The nature of intelligence used should also be a focus of interest: do IUs tailor adequately information dedicated to CSEs? Is forensic intelligence adequately implemented? What is the part of tacit vs. structured knowledge influencing crime scene investigation? Do academics employed, by the police, as CSEs, are more or less prone to the use of intelligence? 
These are questions our study does not pretend to answer. A qualitative approach combining one-to-one interviews and/or focus group, together with field observations, could be consider to conduct further studies on crime intelligence and crime scene investigation. They would clarify and emphasis on the diverse roles CSEs actually play, but that organisations usually fail to attribute them.

\section{Références}

[1] Cope N. Intelligence Led Policing or Policing Led Intelligence. British Journal of Criminology. 2004; 44:188-203.

[2] John T, Maguire M. Rolling Out the National Intelligence Model: Key Challenges. In: Bullock K, Tilley N, editors. Crime Reduction and Problem Oriented Policing. Portland: Willian; 2003. p. 38-68.

[3] Ratcliffe J. Intelligence-Led Policing. Cullompton, UK: Willan; 2008.

[4] Tilley N, Ford A. Forensic Science and Crime Investigation. In: Webb B, editor. Crime Detection and Prevention. London: Police Research Group, Home office; 1996.

[5] Blakey D. Under the Microscope Refocused. A Revisit to the Thematic Inspection. Report on Scientific and Technical Support. Ditching: Her Majesty's Inspectorate of Constabulary; 2002.

[6] Bradbury S-A, Feist A. The Use of Forensic Science in Volume Crime Investigations: a Review of the Research Literature. Online Report. Londres: Home Office; 2005.

[7] Mennell J, Shaw I. The Future of Forensic and Crime Scene Science Part I - A UK Forensic Science User and Provider Perspective. Forensic Science International. 2006; 157:S7-S12.

[8] Tilley N, Townsley M. Forensic Science in UK Policing: Strategies, Tactics and Effectiveness. In: Fraser J, Williams R, editors. Handbook of Forensic Science. Cullompton: Willan; 2009. p. 359-79.

[9] Morelato M, Baechler S, Ribaux O, Beavis A, Tahtouh M, Kirkbride P, et al. Forensic Intelligence Framework. Part I: Induction of A Transversal Model by Comparing Illicit Drugs and False Identity Documents Monitoring. Forensic science international. 2014; 236:181-90.

[10] Baechler S, Morelato M, Ribaux O, Beavis A, Tahtouh M, Kirkbride P, et al. Forensic intelligence framework. Part II: Study of the main generic building blocks and challenges through the examples of illicit drugs and false identity documents monitoring. Forensic Science International. 2015; 250:44-52.

[11] Ribaux O, Baylon A, Roux C, Delémont O, Lock E, Zingg C, et al. Intelligence-led Crime Scene Processing. Part I: Forensic Intelligence. Forensic Science International. 2010; 195:10-6. 10.1016/j.forsciint.2009.10.027

[12] Ribaux O, Baylon A, Lock E, Roux C, Delémont O, Zingg C, et al. Intelligence-led Crime Scene Processing. Part II: Intelligence and Crime Scene Examination Forensic Science International. 2010; 199:63-71. 10.1016/j.forsciint.2010.03.011

[13] Schuliar Y, Crispino F. Semiotics, Heuristics, and Inferences Used by Forensic Scientists. In: Houck M, Siegel JA, editors. Encyclopedia of Forensic Science. 2nd edition ed. Waltham: Academic Press; 2013. p. 310-3.

[14] Inman K, Rudin N. Principles and Practice of Criminalistics: the Profession of Forensic Science. Boca Raton: CRC Press LLC; 2001.

[15] Felson M, Clarke RV. Opportunity Makes the Thief: Practical Theory for Crime Prevention. Police Research Series. London: Home Office, Research, Development and Statistics Directorate, Policing and Reducing Crime Unit; 1998.

[16] Locard E. L'enquête criminelle et les méthodes scientifiques. Paris: Flammarion; 1920.

[17] Barclay D. Using Forensic Science in Major Crime Inquiries. In: Fraser J, Williams R, editors. Handbook of Forensic Science. Cullompton: Willan; 2009. p. 337-58. 
[18] Crispino F. Nature and Place of Crime Scene Management within Forensic Sciences. Science \& Justice. 2008:24-8.

[19] Williams R, Weetman J. Enacting Forensics in Homicide Investigations. Policing and Society. 2013; 23:376-89.

[20] Ludwig A, Fraser J, Williams R. Crime Scene Examiners and Volume Crime Investigations: An Empirical Study of Perception and Practice. Forensic Science Policy \& Management: An International Journal of Police Science and Management. 2012; 3:53-61.

[21] Wyatt D. Practising Crime Scene Investigation: Trace and Contamination in Routine Work. Policing and Society. 2014; 24:443-58. 10.1080/10439463.2013.868460

[22] Roux C, Crispino F, Ribaux O. From Forensics To Forensic Science. Current Issues in Criminal Justice. 2012; 24:7-24.

[23] Robertson J. Forensic science, an Enabler or Disenabler for Criminal Investigation? Australian Journal of Forensic Sciences. 2012; 44:83-91.

[24] Bitzer S, Albertini N, Lock E, Ribaux O, Delemont O. Utility of the Clue - From Measuring the Investigative Contribution of Forensic Science to Supporting the Decision to Use Traces. In press. 2015. 10.1016/j.scijus.2015.05.005

[25] Ludwig A, Fraser J. Effective use of forensic science in volume crime investigations: Identifying recurring themes in the literature. Science and Justice. 2013; 54:81-8.

[26] Kelty S, Julian R, Robertson J. Professionalism in Crime Scene Examination: The Seven Key Attributes of Top Crime Scene Examiners. Forensic Science Policy and Management. 2011;2:175-86.

[27] Hazard D. La pertinence en science forensique. Une (en)quête épistémologique et empirique. Lausanne: Université de Lausanne; 2014.

[28] Ribaux O, Crispino F, Delémont O, Roux C. The Progressive Opening of Forensic Science Towards Criminological Concerns Security Journal. 2015:In press.

[29] Bell C. Concepts and Possibilities in Forensic Intelligence. Forensic science international. 2006; 162:38-43.

[30] Milne R. Forensic Intelligence. Boca Raton: CRC; 2012.

[31] Schuliar Y. La coordination scientifique dans les investigations criminelles. Proposition d'organisation, aspects éthiques ou de la nécessité d'un nouveau métier [Doctoral dissertation]. Paris et Lausanne: Université Paris 5 - Descartes Faculté de Médecine and Université de Lausanne, Institut de Police Scientifique; 2009.

[32] Birrer S. Analyse systématique et permanente de la délinquance sérielle. Place des statistiques criminelles; apport des approches situationnelles pour un système de classification; perspectives en matière de coopération [Doctoral Dissertation]. Lausanne: Université de Lausanne; 2010.

[33] Ribaux O, Birrer S. Iterative Development of Co-operation within an Increasingly Complex Environment. Example of a Swiss Regional Analysis Centre In: Lemieux F, editor. International Police Cooperation Emerging Issues, Theory and Practice. Portland: Willan; 2009. p. 81-100.

[34] Rossy Q, Ioset S, Dessimoz D, Ribaux O. Integrating Forensic Information in a Crime Intelligence Database. Forensic Science International. 2013; 230:137-46. 10.1016/j.forsciint.2012.10.010

[35] Santtila P, Korpela S, Häkkänen H. Expertise and Decision-Making in the Linking of Car Crime Series Psychology, Crime and Law. 2004; 10:97-112.

[36] Ribaux O, Birrer S, Walsh SJ. A trhee level architecture for the analysis of serial burglary that integrates crime mapping tools and forensic case data. In: International FS, editor. 3rd European Academy of forensic Science Meeting. Istanbul, Turkey2003.

[37] Margot P. Commentary on the Need for a Research Culture in the Forensic Sciences. UCLA Law Review. 2011; 58:795-801. 
[38] Margot P. Forensic Science on Trial - What Is the Law of the Land? Australian Journal of Forensic Sciences. 2011; 43:89-103.

[39] Maxfield MG, Babbie E. Research methods for criminal justice and criminology (6th ed.). Belmont, CA: Thomson Wadsworth; 2010.

[40] Girod A, Champod C, Ribaux O. Les traces de souliers. Lausanne: Presses Polytechniques et Universitaires Romandes; 2008.

[41] Baylon A. L'utilisation du renseignement forensique pour guider les décisions liées à l'investigation de scène de crime. Revue Suisse de Criminologie. 2012:40-6.

[42] Adderley R, Townsley M, Bond J. Use of Data Mining Techniques to Model Crime Scene Investigator Performance. Knowledge-based Systems. 2007; 20:170-6.

[43] Jansson K. Volume Crime Investigations: A Review of the Research Literature. Findings. London: Home Office, Research, Development and

Statistics Directorate; 2005.

[44] Burrows J, Tarling R. Measuring the Impact of Forensic Science in Detecting Burglary and Autocrime Offences. Science \& Justice. 2004; 44:217-22.

[45] Crispino F. La trace matérielle. Un catalyseur d'exploitation de l'information judiciaire. . Revue de la gendarmerie nationale 2006:5-15.

[46] Crispino F. Analyse de la scientificité des principes fondamentaux de la criminalistique [Doctoral dissertation]. Lausanne: Université de Lausanne; 2006.

[47] Rix B. The Contribution of Shoemark Data to Police Intelligence, Crime Detection and Prosecution. Findings London: Home Office, Research, Development and Statistics Directorate; 2004.

[48] Ribaux O, Walsh SJ, Margot P. The Contribution of Forensic Science to Crime Analysis and Investigation: Forensic Intelligence. Forensic Science International. 2006; 156:171-81.

[49] Williams R. The Management of Crime Scene Examination in Relation to the Investigation of Burglary and Vehicle Crime. Findings: Home Office; 2004.

[50] Aebi M, Jaquier V. Les sondages de délinquance autoreportée : origines, fiabilité et validité. Déviance et Société. 2008; 32:205-27.

[51] Jamieson A. A Rational Approach to the Principles and Practice of Crime Scene Investigation: I. Principles. Science \& Justice. 2004.

[52] Dror I. The Ambition to be Scientific: Human Expert Performance and Objectivity. Science \& Justice. 2013; 53:81-2. 10.1016/j.scijus.2013.03.002

[53] Dror I. Letter to the Editor-Combating Bias: The Next Step in Fighting Cognitive and Psychological Contamination. Journal of Forensic Sciences. 2012; 57:276-7. 10.1111/j.15564029.2011.01940.x

[54] Laurin J. Remapping the Path Forward: Toward a Systemic View of Forensic Science Reform and Oversight Texas Law Review 2013; 91:1051-118. 
Response to reviewers:

Reviewer: Manuscript referred to 2 questionnaires but there is a lack of details about themselves (how many questions, what kind of questions? etc.). Would it be possible to add them in annex or in supplementary data? It would help to improve understanding, particularly with regard to the first parts of results (from 6.1 to 6.4 paragraphs) and to better understand tables

We have consolidated the description of the questionnaire, and of its methodological justification. In particular, we have added into the text(page 5-6) a sample of questions asked. They have been translated into english. It would cause a lot of difficulties (also methodological) to translate precisely the whole questionnaire in order to make it available as an annex.

Reviewer: Paragraph 6.2, page 8, it is mentioned that the subpopulation is principally constituted by males (60,5\% males vs. $43,7 \%$ females) 11 , aged 40 to 55 (66,7\% vs. $51,2 \%$ in those aged 24 to 39 ) with an academic background (63,6\% vs. $50 \%$ in those with a police background)... To which type of academic background is referred? Could the author be more specific?

'with an academic background'

has been changed in:

'with an academic background acquired principally from the forensic school of University of Lausanne'

We cannot guarantee that the totality of the respondents answering 'academic background' have this specific academic background. We can attest however this is a very large majority. This aspect may be part of the explanation to the obtained results. It has been discussed in the conclusion.

Concerning reference style, authors should use the FSI Guide for Authors.

The reference guide to authors states:

«There are no strict requirements on reference formatting at submission. References can be in any style or format as long as the style is consistent »

We have however downloaded the format used by Forensic Science international into Endnote and re-formatted reference and bibliography according to this format.

We have eventually added some minor modifications throughout the text, according to remarks obtained from the presentation of these results in different contexts (academic and professional) 